\title{
Embracing Industrial Revolution 4.0: The Effect of Using Web 2.0 Tools on Primary Schools Students' Mathematics Achievement (Fraction)
}

\author{
Nurulwahida Azid \\ Assoc. Prof., Universiti Utara Malaysia, Malaysia, nurulwahida@uum.edu.my
}

Rozita Hasan

Universiti Utara Malaysia, Malaysia,rozita_hasan@ahsgs.uum.edu.my

Nurul Fazilah Mohamad Nazarudin

Universiti Utara Malaysia, Malaysia, nurulfazilah9039@gmail.com

\section{Ruzlan Md-Ali}

Universiti Utara Malaysia, Malaysia, ruzlan@uum.edu.my

\begin{abstract}
Students' sound knowledge of mathematical concepts is important for the development of their mathematical knowledge to support the more challenging application skills at higher levels of mathematics learning. Diverse classroom teaching strategies with appropriate teaching tools are crucial to ensure that students meaningfully achieved the set learning outcomes. The use of web 2.0 tools enabled students to communicate actively with their peers and teachers during lessons. This quasi-experimental study with a mixed method approach involving pre-test and post-test was conducted to examine the effect of using web 2.0 tools on students' mathematical achievement. 60 Year Five students were randomly divided into two groups, namely the control and the experimental groups. The experimental group was taught using the Direct Instruction (DI) Model of teaching strategy with web 2.0 tools while the control group was taught using the DI Model of teaching strategy without web 2.0 tools. The teaching strategy that used web 2.0 tools has not only brought about the increase in students' mathematics achievement but has also motivated them to complete the tasks given during the lessons. The findings of this study also showed that students' learning of mathematics in the classroom was fun and they became more interested with the usage of 2.0 tools. So, mathematics teachers need to be continuously trained to enhance their teaching competence to meet the challenges of incorporating technology in their classrooms.
\end{abstract}

Keywords: web 2.0 tools, quasi-experimental design, mixed method research, mathematics achievement, teaching strategy, direct instructional model

Citation: Azid, N., Hasan, R., Nazarudin, N. F. M., \& Md-Ali, R. (2020). Embracing Industrial Revolution 4.0: The Effect of Using Web 2.0 Tools on Primary Schools Students' Mathematics Achievement (Fraction). International Journal of Instruction, 13(3), 711-728. https://doi.org/10.29333/iji.2020.13348a 


\section{INTRODUCTION}

Curriculum implementers need to preserve the curriculum changes to be relevant and in line with the Industrial Revolution 4.0 (UNESCO Institute for Statistics, 2017). The explosion of Industry Revolution 4.0 has also given an impact on the education sector in terms of curriculum preparation, teaching techniques, the provision of learning experiences, learning activities and assessment to be in line with 21 st century education (Hussin, 2018). The Industrial Revolution (IR) 4.0 aspiration is to produce efficient and effective source and manpower to meet the needs of human capabilities (Hussin, 2018). Therefore, international education policy in the United States has put emphasis on the implementation of technology in the classroom for the production of competitive manpower in terms of cognition and competency (Chai, 2018). The contribution of technology integration supports pedagogical reforms in education including in the field of mathematical education ( $\mathrm{Ng}$, Teo, Yeo, Ho \& Teo, 2019). Mathematical teaching and learning too is not exempted from using technology as a catalyst in mathematical pedagogy. Among them is the use of the framework of Technological Pedagogical Content Knowledge (TPACK) in teaching mathematics and the learning process is found to be more interesting (Bustamante, 2017). TPACK is a framework that illustrates the interaction between technology use, pedagogy and knowledge of learning content (content knowledge) (Chai, 2018). The culture of applied technology in mathematics, whether analog and digital, shows the interaction of technology in mathematical pedagogy. According to Hoyles (2018) the use of digital technology tools such as web 2.0 tools can change the teaching of mathematics in the classroom. This is because according to Hoyles (2018), digital tools such as this is dynamic dan offers capivating graphics when teaching mathematics. The use of web 2.0 tool also exploits the use of the internet which stimulates students' interest and motivation to learn mathematics (Buckley \& Doyle, 2016).

\section{Research Background}

UNESCO Institute for Statistics (2017) has created an awareness campaign on the importance of acquiring mathematical education among the community, especially for teens and children. This opinion is supported by a study conducted by Chai (2018) regarding the importance of having mathematics skills and education among children globally. According to Hasler and Akshoomoff (2019), the study of the importance of mathematical education is also supported by the International Mathematics Union (IMU) and the African Mathematical Union (AMU) which emphasized that every child should have basic mathematical skills. In parallel with that effort, children's interest in mathematics should be well-directed through technology-based teaching strategies such as the use of web 2.0 tools (Zaranis \& Synodi, 2017). Therefore, teachers need to be more open and creative in implementing pedagogy through technology to influence students' interest (Buckley \& Doyle, 2016). Application of Information Communication Technology (ICT) in pedagogy can attract students to be more positive towards mathematics (Bustamante, 2017). Interesting and creative delivery methods such as ICT usage, Computer Assisted Learning (CAL) and web 2.0 tools by teachers can attract students to learning (Lai, 2017). 


\section{Knowledge of fractions}

Fraction is a crucial component of the mathematics curriculum in elementary and middle schools throughout the world. Fraction topic are introduced to primary students after entering the first year of schooling (Ye, Resnick, Hansen, Rodrigues, Rinnie \& Jordan, 2016). Yet there are students who face great confusion when dealing with fractions and their magnitudes (Kor, Teoh, Mohamed \& Singh, 2019). Many students who are less interested in Mathematics become even more paranoid with the subject after being taught the fraction topic (Lamon, 2008). The content in fractions is complex, yet it is an important concept in mathematics (Kor, Teoh, Mohamed \& Singh, 2019). Literature on children's learning of fractions indicated that children are experiencing various difficulties when learning fractions. For instance, they face difficulties in translating decimals into fractions (Kloosterman, 2010), struggling when making fraction magnitude comparisons (Wijaya, 2017). There are students who failed to identify that both the numerator and denominator determine the fraction's magnitude. Failure to comprehend basic notion of fractions could result in failure to acquire other mathematics topics. Knowledge of fractions provides the foundations for algebraic thinking and proportional reasoning (Wijaya, 2017). Being competent in fractional knowledge will assist the learning of algebra and knowledge of algebra will in turn prepares students for higher level of education of mathematics as well as their careers in science, technology, and engineering. Knowledge of fractions is greatly used in numerous calculation and measurements (Wijaya, 2017). Kloosterman (2010) stressed the importance of the fraction topic in mathematics education as basic knowledge for other areas of mathematics such as percentages, rate and ratio, and decimal. Additionally fraction knowledge can be applied in our everyday lives when dealing with calculating time, measuring length and weighing objects (Wijaya, 2017).

\section{Integration of technology in mathematical teaching}

The topic of fractions is already introduced to primary students after entering the first year of schooling (Ye, Resnick, Hansen, Rodrigues, Rinnie \& Jordan, 2016). Therefore, the choice of teaching methods appropriate to the age of the students should be taken into account to ensure that learning sessions are well and effective (Zaranis \& Synodi, 2017). In general, mathematics subject emphasizes conceptual and practical understanding. Understanding clear concepts needs to be well mastered by students and practiced in learning and everyday life (Hiebert, Miller \& Berk, 2017). The study findings in Indonesia by Simamora, Saragih and Hasratuddin (2018) found that the level of students' mastery in mathematics was very weak and the students were less interested in the subject as it was difficult to understand which in the long run affected achievement. The choice of appropriate teaching methods can lead to increased student understanding of mathematics (Simamora, Seragih \& Hasratuddin, 2018). For example, the application of constructivism theory in pedagogy helps students to incorporate existing knowledge and learned facts while improving the students' mastery (Yusmarni, 2018).

Chai (2018) states that the integration of Science, Technology, Engineering, and Mathematics (STEM) in the education world has been based on two major 
developments namely mathematics and science. These two basic subjects are the starting point for the integration of technology in mathematics teaching. Teachers' skill in integrating technology as the latest pedagogical tool in teaching is a great effort to embrace the use of ICT in teaching (Ghavifekr \& Rosdy, 2016). Technology in education helps teachers in providing teaching aids that suit the needs, levels and diversity of students (Lee, 2017). The application of technology in mathematical education helps teachers carry out better, effective and innovative teaching processes for students as early as 7 to 12 years (Lee, 2017). The application of technology in mathematical education gives students the opportunity to practice the knowledge and skills learned to solve problems (Orey \& Rosa, 2018). The appropriate application of technology facilitates students' understanding in making calculations from easy to advanced levels.

Creative teaching patterns through technology applications can enhance teachers' ability to identify potential students in solving problems involving critical thinking processes (Orey \& Rosa, 2018). The use of appropriate teaching methods in mathematics has an impact on the knowledge and skills acquired by the students. Hence, they will be able to solve problems, collect data, process the data and draw conclusions or hypotheses (Godfrey \& Brown, 2018). Putri and Saputro (2019) stated that teachers were able to improve student achievement in mathematics by providing clear guidance using more creative delivery methods such as technology application in the process of information delivery. This method was able to increase the level of student's mastery in solving problems related to mathematics. Clear learning goals can make students more aware of the ways and functions of mathematics as well as improving the level of mastery of the students (Orey \& Rosa, 2018). In addition, students were also able to apply the mathematical knowledge gained in their daily lives (Zhao, Ho, Toh, Hang \& Teo, 2019).

\section{Web 2.0 tools in mathematics}

Technology-based teaching consists of several key mediums, including web 2.0, also known as effective interactive media in an effort to improve students' achievement in the classroom (Bustamante, 2017). Web 2.0 tools have dominated creative teaching patterns in the classroom, such as the application of theory using ICT technology and further expanded to practical calculations. A study by Bustamante (2017) proved that this web 2.0 is one of the branches of an effective pedagogical method for use in mathematical learning activities. This was also supported by Ellis and Bond (2018) who agreed that the application of ICT technology was able to reduce the comprehension gaps in the teaching and learning process in the classroom.

The appropriate pedagogical methods in learning, especially for mathematics help to improve students' understanding (Shapira \& Zavelevsky, 2019). The use of web 2.0 tools was one of the teaching methods adopted in mathematics and its application was able to change the perceptions of students who were not interested in mathematics $(\mathrm{Ng}$, Teo, Yeo, Ho \& Teo, 2019). Padlet is one of the applications contained in web 2.0 tools that are often used in mathematical teaching (Kleinsmith, 2017). Haris, Yunus and Badusah (2017) stated that the use of padlet as an interactive communication field was capable of supporting the method used by students in problem solving. Padlet 
applications can make it easy for students to share ideas, discuss and extend their mathematical understanding in a clearer and more interesting way (Kleinsmith, 2017). The use of web 2.0 tools has attracted interest and changed students' negative perception of mathematics because it created a fun learning environment (Graham, Mokgwathi \& Fraser, 2018).

\section{Direct instruction model of teaching}

Direct Instruction (DI) is a carefully designed and clear lesson model to explain about a concept to students to achieve goals in teaching (Joyce \& Weil, 2003). Cynthia, Margaret and Margaret (2018) who conducted a DI study on the autism population and the disabled in the "reading comprehension" program has shown that there is a significant impact in improving their achievement. The findings also show DI is the best teaching model to be applied in reading comprehension skills to autism and disability groups. This finding is also supported in a study by Deutsch (2019) who has conducted a DI study on the subject of mathematics and the findings showed that DI can provide support to students who were not excellent in mathematics. There are four principles that are used as guidance in the implementation of DI in schools. These four principles are combined and can guide that teaching session should begin with (i) introduction and review, (ii) presentation (iii) guided practice and (iv) independent practice (Joyce \& Weil, 2003).

\section{Research Questions}

1. What is the mathematics (fraction topic) achievement level of the Year Five students in pre-test and post-test for control and treatment groups?

2. Is there any significant difference between the Direct Instruction Model of Teaching without web 2.0 tools and the Direct Instruction Model of Teaching with web 2.0 tools on the achievement of mathematics (fraction topic) among the Year Five students?

3. What are the students' views of using web 2.0 tools as a mathematical learning tool for fraction topic?

\section{Research Hypothesis}

$\mathrm{H}_{0} 1$ : There is no significant difference between the Direct Instruction Model of Teaching with web 2.0 tools on the achievement of mathematics (fraction topic) among the Year Five students.

\section{METHOD}

\section{Research Design}

This study used a quasi-experimental pre and post-test design using both quantitative and qualitative approaches (Creswell, 2014; Fraenkel, Wallen \& Hyun, 2015). The purpose of this study was to measure mathematical achievement through experiments using Direct Instruction Model of Teaching with web 2.0 as a pedagogical tool in teaching mathematics (Lai, 2017; Cresswell, 2014). The dependent variable in this study 
was the mathematics achievement post test on the fraction topic. While the independent variables were two groups studied, the control group (using the Direct Instruction Model of Teaching without web 2.0 tools) and the treatment group (using the Direct Instruction Model of Teaching with web 2.0 tools). This study used the padlet to examine the effectiveness of web 2.0 tools as a teaching technique to improve mathematical achievement among Year Five students. The design of this study is illustrated in Table 1.

Table 1

Quasi-Experimental Design

\begin{tabular}{|c|c|c|c|}
\hline Group & & Teaching Method & \\
\hline Control Group & Pre Test & $\begin{array}{l}\text { Direct Instruction Model of Teaching without web } \\
2.0 \text { tools }\end{array}$ & Post Test \\
\hline $\begin{array}{l}\text { Experiment } \\
\text { Group }\end{array}$ & Pre Test & $\begin{array}{l}\text { Direct Instruction Model of Teaching with web } \\
2.0 \text { tools }\end{array}$ & Post Test \\
\hline
\end{tabular}

Qualitative and quantitative approaches were used in this study to get a holistic picture without any elements of manipulation from researchers (Gardner, 2015). Data from both approaches were used to support research findings from multiple sources and to show a holistic view of the effectiveness of treatment. The interview method was used to support quantitative findings from pre-test and post-test (Gardner, 2015).

\section{Participants}

The participants of the study were 60 students among 11-year-old students (Year Five) from a primary school in the Kubang Pasu district selected as the respondents of the study. Students were divided into two groups of 30 placed randomly in control and treatment groups (Cresswell, 2014). The treatment group has undergone a teaching and learning session using Direct Instruction Model of Teaching with web 2.0 tools, while the control group underwent conventional teaching sessions, Direct Instruction Model of Teaching without using web 2.0 tools. Conventional teaching methods in the control group were based on teaching using the Year Five mathematics textbooks released by the Ministry of Education (Curriculum Development Division, 2014). Consequently, a total of 10 students who have been taught in Direct Instruction Model of Teaching with web 2.0 tools were randomly selected to undergo face-to-face interviews (Braun \& Clark, 2013).

\section{Instrument}

The instrument used consisted of 30 fraction questions taken from the Mathematic module of the Kubang Pasu District Education Office. The test questions consisted of skills learned in the year five. The skills tested were a continuation of the skills learned from year four. The taught and tested sub-topics consisted of basic fractional operations namely addition, subtraction and multiplication and problem solving.

\section{Reliability}

The research instrument was composed of a set of mathematical questions containing 30 multiple choice items for fraction topic. The total score was $100 \%$. This instrument was 
used as pre test and post test. Pilot study was conducted on 50 students (not a sample of the study) to obtain the reliability of the instruments. The results of the pilot study showed that the reliability of the instrument was 0.89 using KR20. Instrument item construction was based on Bloom's Taxonomy which included six levels cognitive domains namely, remembering, understanding, applying, analyzing, and evaluating (Hem \& Ravinesh, 2017). The scoring was based on the scoring standard of primary school mathematics public examination in Malaysia and according to Mastery Level (Curiculum Development Division, 2014)

\section{Face and content validity}

Face validity and content validity were performed on all items contained in the pre-test and post-test. This validity was done by a Kubang Pasu District Education Officer and three specialist teachers in mathematics. The purpose of face and content validity was to ensure that each item coordinated with the level of Bloom Taxonomy and the level of content of the subject for the five year fraction topic based on the Standard Document of the Curriculum and Mathematical Assessment of the Ministry of Education, Malaysia (Curiculum Development Division, 2014).

\section{Teaching activities using the direct instruction model of teaching web 2.0 tools}

Teaching sessions for treatment groups used web 2.0 tools as a pedagogical tool in the classroom. Among the web 2.0 programs used was Padlet as one of the mathematical learning activities for fraction topic. Padlets are virtual wall that can be an interactive field for students to load answers and teaching notes; to collaborate with fellow classmates and teachers (Kleinsmith, 2017). The advantages of the padlets are that teachers can upload materials and assignment questions to the wall. The students held discussions and included mathematical answers (fractions) into the wall for review with other groups. The integration of iThink mind map was used to measure fractional concepts using circle maps (Hyerle, 2009). According to the Curriculum Development Center (2012) there are eight i-THINK maps to be introduced to students: circle map (defining in context), bubble map (describing qualities), double bubble map (comparing \& contrasting), brace map (whole-parts relationship), flow map (sequencing), multi-flow map (analysing cause and effect), and bridge map (related factor). In this study only the circle map was applied in mathematics teaching.

The results of the group discussion were uploaded in the padlet wall and discussed together (Refer to Figure 1). Fractional problem solving activity (for low, medium and high) was carried out by students using the worksheets and uploaded in padlets to be checked with teachers and students (Refer Figure 2). Teaching sessions were conducted in four sessions separately that took three hours and fulfilled the time allocated for the teaching of fraction topic (Curiculum Development Division, 2014). 




Figure 1

Result of Group Discussion in the Padlet Wall

Diagram 1 shows an example of a discussion conducted in a padlet application between a teacher and a student. The wrong question has been circled red while the correct answer has been marked correctly. Students also communicated in the padlet to discuss answers that have been uploaded in the padlet application. 


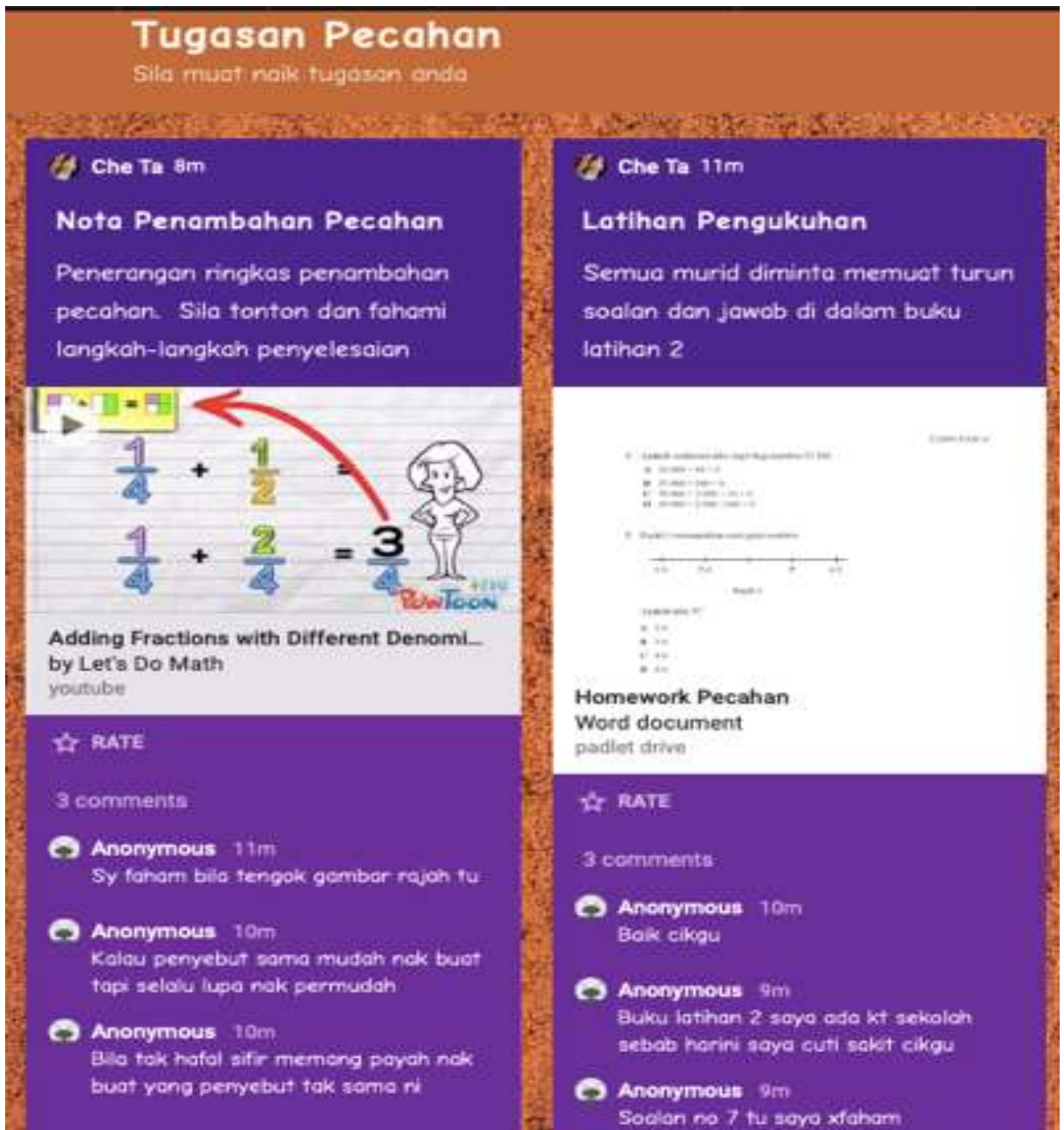

Figure 2

Fractional Tasks

Figure 2 shows the notes that teachers have uploaded in the padlet application in preparation for class. Students used the padlet application as a communication field to discuss assignments and notes given by the teacher. Teachers also responded to students' questions using the padlet application. 


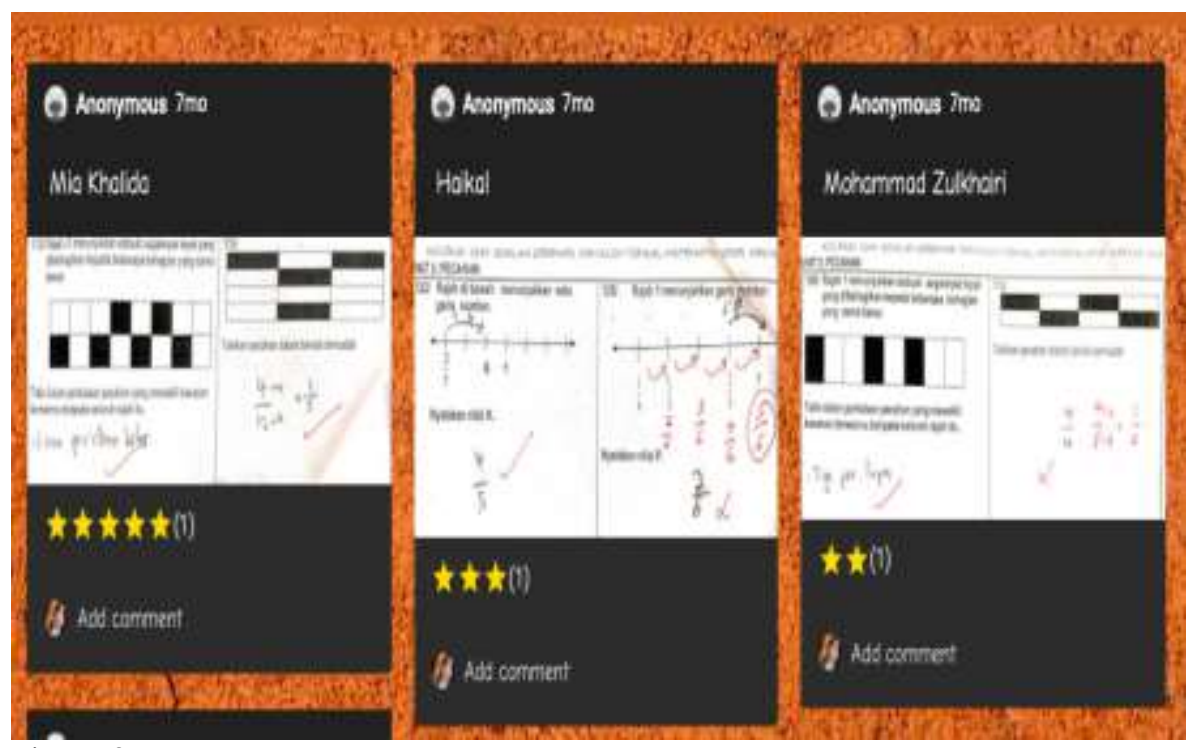

Figure 3

Students' Tasks

Figure 3 shows students' tasks that have been uploaded in the padlet application and each question has been discussed virtually. Each uploaded question was different because each group assignment was different according to different levels. This application made it easy for students to review the steps taken when they answered the questions. Padlet usage has also encouraged interaction between teachers and students.

\section{Conventional method direct instruction model of teaching without web 2.0 tools}

The conventional teaching method is a teacher-centered teaching method delivered to students. In this study, teacher teaching via conventional method used traditional information techniques such as whiteboard, textbooks and workbooks. Teacher explained each fraction work and then the students answered the questions given by the teacher as reinforcement of the teaching process in the classroom (Deutsch, 2019). Teaching session was conducted in four sessions separately which took three hours and fulfilled the Standard Curriculum and Assessment Document (Curiculum Development Division, 2014).

\section{Data Collection Procedure}

The data collection process began with a meeting with the school administrators and teachers to set the appropriate dates for pre-test, post-test and suitable time to conduct treatment sessions so as not to interfere with the current school session. Researchers have also made sure that the post-test implementation period was accurate to the correct time period of one month after the pre-test (Cresswell, 2014; Fraenkel, Wallen \& Hyun, 2015). Students were given pre-test in the first week. After pre-test, treatment sessions were conducted on the second week to week 5. Post-test was conducted in the sixth 
week. Post-test took place within a month after the pre-test and met the criteria for conducting the quasi-experimental (Cresswell, 2014; Fraenkel, Wallen \& Hyun, 2015). Meanwhile, qualitative data was collected through interviews conducted after treatment.

\section{Data Analysis}

The SPSS program was used to obtain descriptive analysis using the percentage to measure the achievement of mathematics among students (Chua, 2012) while ANCOVA analysis was used to see the effect of using the Web 2.0 Direct Instruction Model of Teaching Strategy on the achievement of Year Five mathematics students (fraction) (Chua, 2012). ANCOVA analysis was used to compare mean values for control groups and treatment groups before and after treatment sessions (Chua, 2012). ANCOVA analysis was conducted to explore the differences between groups by controlling the increment of variables (covariate) (Chua, 2012). Students' level of achievement analysis for pre-test and post-test are as follows:

(i) $80 \%-100 \%$ Excellent

(ii) $60 \%-79 \%$ Good

(iii) $30 \%-59 \%$ Satisfactory

(iv) $0 \%-39 \%$ Weak

Data from interview sessions was recorded, transcribed by researchers for data analysis purposes as suggested by Braun and Clark (2013). The findings of the data were analyzed using a thematic analysis ie by compiling all the findings and concluding them based on the theme (Braun \& Clark (2013). Data was analyzed and compiled into themes such as learning using web 2.0 tools were fun, easy to use, easy to conduct discussions between teachers with students and peers. Qualitative analysis involved ten respondents $(n=10)$ randomly selected for the interview session. The purpose of the interview was to get feedback on teaching implementation using web 2.0 tools in fraction topic. The interview session was conducted after the learning of fraction topic to get the Year Five students' view of the use of padlets in teaching. Interviews were conducted face-to-face for 20 minutes after the school session. Interviews were conducted using students' mother tongue (Malay Language) as students were more comfortable to answer the interview questions using their daily spoken language and with unscripted sentence structure (Gardner, 2015). Students were asked to share their feelings throughout the Mathematical learning process using web 2.0 tools and their impact on student knowledge on fraction topic.

\section{FINDINGS}

The findings are reported in two parts, namely quantitative and qualitative.

\section{Quantitative Results}

Descriptive analysis is reported based on Table 2 and Table 3 to explain the level of achievement of Year Five students on the achievement of mathematics for fraction topic. Table 2 shows the achievement of students in pre test and post test. The findings from the pre-test showed that students' achievement in fraction topic was moderate at $7 \%(\mathrm{n}=$ $2)$ and a large proportion was weak at $93 \%(n=28)$. However, post-test showed that the decline in the number of weak students to $23 \%(\mathrm{n}=7)$ compared to the post-test. 
Table 2

Pre-Test and Post-Test for Control Groups

\begin{tabular}{llllll}
\hline Method & Category & Pretest & \multicolumn{3}{c}{ Posttest } \\
\cline { 3 - 6 } & & $f$ & $\%$ & $f$ & $\%$ \\
\hline \multirow{2}{*}{ Direct Instruction } & Excellent & & & 3 & 10 \\
Model of Teaching & Good & & & 9 & 30 \\
without web 2.0 tools & Satisfactory & 2 & 7 & 11 & 37 \\
& Weak & 28 & 93 & 7 & 23 \\
\hline
\end{tabular}

Table 3 shows the achievement level of treatment group students in pre test and post test. Preliminary tests indicated students' achievement levels were at satisfactory level of $10 \%(\mathrm{n}=3)$ and weak $90 \%(\mathrm{n}=27)$. While post-test showed improvement compared to pre-test. The findings showed that students who were excellent was $17 \%(\mathrm{n}=5)$, good was $23 \%(\mathrm{n}=7)$, satisfactory $50 \%(\mathrm{n}=15)$ and weak $10 \%(\mathrm{n}=3)$.

Table 3

Pre-Test and Post-Test for Treatment Groups

\begin{tabular}{llllll}
\hline Method & Category & Pretest & \multicolumn{2}{l}{ Posttest } \\
\cline { 3 - 5 } & & $f$ & $\%$ & $f$ & $\%$ \\
\hline \multirow{2}{*}{ Direct Instruction } & Excellent & & & 5 & 17 \\
Model of Teaching & Good & & & 7 & 23 \\
with web 2.0 tools & Satisfactory & 3 & 10 & 15 & 50 \\
& Weak & 27 & 90 & 3 & 10 \\
\hline
\end{tabular}

ANCOVA test analysis was conducted to examine the differences in mathematical achievements for pre and post-fraction topic for control and treatment groups. The requirement for ANCOVA test was that one of the data was required to undergo the Levene's test to ensure both groups were homogenous before treatment was given. Table 4 shows the result of homogeneity test through Levene's test which is insignificant, meaning that both groups were identical at the beginning.

Table 4

Levene's Test

\begin{tabular}{llll}
\hline $\mathrm{F}$ & $\mathrm{df1}$ & $\mathrm{df} 2$ & Sig. \\
\hline .247 & 1 & 58 & .621 \\
\hline
\end{tabular}

Table 5 is the result of the ANCOVA test which showed that there was a significant effect of the independent variable of the Method of Teaching on posttest dependent variables $(\mathrm{F}(2,57)=24.2, \mathrm{p}<.05)$. Furthermore, the results showed that there was a significant effect on the dependent variable in the posttest test $(F(1,57)=11.74, p$ $<.05)$. The results of comparative test results for the topic fraction on the method of teaching indicated that the differences between all comparison pairs were significant $(p$ $<.05$, after controlling Type I errors using Bonferroni method). The comparison pairs were treatment group - control group (the difference in the mean of post-mathematical achievement test (fraction) $=5.10, \mathrm{p}<.05$ ) and treatment group - control group obtaining significant results. 
Table 5

ANCOVA Tests (Method of Teaching)

\begin{tabular}{|c|c|c|c|c|c|}
\hline \multicolumn{6}{|c|}{ Dependent Variable: Posttest } \\
\hline Source & Type III Sum of Squares & $\mathrm{df}$ & Mean Square & $\mathrm{F}$ & Sig. \\
\hline Corrected Model & $107.289^{\mathrm{a}}$ & 2 & 53.645 & 19.390 & .000 \\
\hline Intercept & 174.476 & 1 & 174.476 & 63.066 & .000 \\
\hline Pretest & 32.472 & 1 & 32.472 & 11.737 & .001 \\
\hline Method of Teaching & 66.952 & 1 & 66.952 & 24.200 & .000 \\
\hline Error & 157.694 & 57 & 2.767 & & \\
\hline Total & 1217.000 & 60 & & & \\
\hline Corrected Total & 246.983 & 59 & & & \\
\hline
\end{tabular}

${ }^{\mathrm{a}}$. R Squared $=.405$ (Adjusted R Squared $=.384$ )

\section{Qualitative Results}

For the overall results of the interview findings, the researchers identified the themes that existed in the interviews. The themes for mathematics learning sessions using Direct Instruction Model of Teaching with Web 2.0 Tools were more fun, attracted students to enjoy mathematical subjects and gave new experiences in the learning process. The interview findings showed that all students agreed that teaching methods using web 2.0 tools were effective and interesting to be used in classroom learning and this motivated them to learn mathematics. Here are some of the students' responses from the interview session:

"Yes, I obtained a new experience through this learning; more fun and added my motivation to learning mathematics. I think this teaching session has made me love math. Teachers always provided more explanations and additional reference notes can be downloaded from the padlet provided by the teacher. " (M3)

"Mathematics learning on fraction topic using web 2.0 tools was fun. I can finish assignments at home and teachers can check my assignments virtually anywhere even on vacation. Teacher always gave guidance and words to all of us. Through the Padlet I can also see the breakdown solutions broken down by other friends which I can use as a guide when solving a fraction assignment given by the teacher " (M6)

"I feel challenged in this session because I need to use the padlet, but I really liked it because I have a new experience and it has given me a new challenge and I feel good and motivated. Mathematics is no longer just on the whiteboard. I can also share information about fractions in a padlet for other peer references " (M8)

Students found that learning using web 2.0 was a fun teaching session and has given them new learning experiences. Direct Instruction Model with Web 2.0 tools was seen as effective as it combined the teaching of teachers and the padlets. This also gave a meaningful experience to students from different angles for mathematical subjects. As a result of the interview, students' motivation in mathematics for fraction topic was also improved.

\section{DISCUSSION}

The findings of this study were able to answer three research questions, namely (i) student achievement profiles for mathematics of fraction topic through pre- and post- 
test, (ii) significant differences between control and treatment groups based on posttests, (iii) students' views of using web 2.0 tools as a mathematical learning tool for fraction topic. Further, the researcher discusses in in-depth the three findings obtained through quantitative and qualitative methods.

The findings were that the student-mathematics achievement of fraction topic in the control group in the pre- and post-test showed a significant improvement in overall student achievement in the post-test. On the other hand, for the treatment group, the post-test results showed that most students have improved to moderate, good and excellent.

The pre test results showed that the two selected groups were comprised of medium and low achievers. There was a significant difference between in control group compared to the treatment group. Even the achievement of treatment groups using web 2.0 tools was better than teaching without web 2.0 tools. This is in line with Graham, Mokgwathi and Fraser's findings (2018) which also stated that the use of web 2.0 tools has a great impact on the teaching and learning of students in the classroom. This situation proved that there was a favorable impact on the achievement of mathematics for treatment group that used padlets as a medium of teaching mathematic in the fraction topic.

This study found that there was a significant difference between the control and treatment groups on the achievement of five-year mathematics students. This shows that teaching method using web 2.0 tools was better than conventional method. This is because interview data with students showed that learning to use the web 2.0 tools successfully has enhanced their motivation and interest in mathematics. All mathematic problem solving processes could be done through the padlet and students could get instant feedback from peers and teachers. Learning to use the web 2.0 tools made it easier for students to download notes provided by teachers through padlets. Furthermore, assignments provided in the padlet gave students the opportunity to complete the assignments at home and teachers were able to browse virtually anywhere. Through the padlet wall all students were able to communicate by sharing notes and completing assignments and thus peer teaching process took place indirectly. Web 2.0 tools usage has provided a space for teachers to monitor every assignment and development of their students' learning at home.

Direct Instruction Model of Teaching is a teaching model used in classroom with web 2.0 tools (group of treatments) and without web 2.0 tools (control group). The treatment group underwent learning activities that promote the interaction of the padlets to check the answers and discuss the assignment given (Haris, Yunus \& Badusah, 2017). Teaching using web 2.0 tools was seen as having a good impact on the students' interest and thus improving their achievement in the classroom. This finding was in line with the findings of Ghavifekr and Rosdy (2016), which showed that the influence of web 2.0's use has a positive impact on students and has increased their motivation and thus affected their achievement. Students were able to interact collaboratively and there was no time limit to discuss the lessons learned. The use of web 2.0 tools enabled teachers to diversify the use of ICT in teaching to improve the quality of teaching and thus improve the quality of student achievement (Lai, 2017). Hence, it can be said that there was a 
link between the findings regarding the use of ICT in the classroom. The IR 4.0 education culture that integrates ICT in mathematical education should be continued to improve the mathematical achievement of students. While this study has proven that a web 2.0 usage is good, there are still some factors that need to be investigated. Some constraints faced in the implementation of web 2.0 use should also be taken into account, especially in the classroom implementation process in terms of constraints from the teacher or the students themselves (Kleinsmith, 2017). Among the constraints identified were the skill of teachers in using web 2.0 in teaching and learning; and a relatively weak internet network problem in certain areas that would limit effective web 2.0 tools usage.

Fun learning methods are one of the important aspects that teachers need to take into account. This is because, students think mathematics is a difficult subject to understand and uninteresting which raises concerns about the subject (Simamora, Saragih \& Hasratuddin, 2018). If student motivation is not improved in the teaching and learning process in the classroom, students will lose interest in mathematics. Hence, the use of web 2.0 tools is one of the alternatives that are relevant to the 21 st century learning.

This study is expected to contribute to teachers to change the way in which mathematics is taught in the classroom. This method will allow the teacher to monitor the level of student achievement in each given assignment. Through this method, the teacher can identify the weakness of the students and can provide direct guidance before the misconception occurs. Teachers can also involve parents in assignments given so that parents can monitor their child's activities virtually (Shapira \& Zavelevsky, 2019).

\section{CONCLUSION}

In conclusion, the quantitative findings of this study have shown that the use of padlet as part of the web 2.0 tools has had a positive impact on students in terms of (i) student achievement scores in mathematic-fraction topic, (ii) performance comparison between control and treatment groups proved that using padlet as a teaching medium has spurred student growth. While the qualitative findings obtained from student interviews proved that the use of padlet as part of the web 2.0 tools has (i) helped attract students to mathematic-fraction topic, (ii) fostering bilateral communication between students and teachers and was not confined to the classroom only ( iii) Mathematic solving activities became easier and more attractive through padlet. The use of web 2.0 tools in teaching in the classroom should be applied by math teachers in particular and other subjects in general to ensure that students accept math as a fun subject. The use of web 2.0 tools is a learning method in parallel with the current trend which responds to the nation education agenda towards the industry revolution 4.0. This study has proven that the use of technology in teaching in the classroom contributes to the improvement of student achievement, interest and motivation. Although this study does not reflect the improvement of student achievement across the country, researchers are of the view that teaching sessions using web 2.0 tools need to be continued to ensure student learning sessions are more meaningful. This study has only focused on the concept of fractions, so it is recommended that other researchers conduct a study of teacher readiness in changing the teaching strategies and methods in the classroom. Among them is the need 
for training to teachers to be sufficient in meeting the competency requirements to implement the use of technology in teaching in the classroom.

\section{REFERENCES}

Braun, V. \& Clark, V. (2013). Successful qualitative research a practical guide for beginners. Thousand Oaks, California: SAGE.

Buckley, P., \& Doyle, E. (2016). Gamification and student motivation. Interactive Learning Environments, 24(6), 1162-1175.

Bustamante, C. (2017). TPACK and teachers of Spanish: Development of a theorybased joint display in a mixed methods research case study. Journal of Mixed Methods Research, 13(2), 163-178.

Chai, C. S. (2018). Teacher professional development for science, technology, engineering and mathematics (STEM) education: A review from the perspectives of technological pedagogical content (TPACK). The Asia-Pacific Education Researcher, 28(1), 5-13.

Chua, Y. P. (2012). Mastering research methods. Selangor: McGraw Hill (Malaysia).

Cresswell, J. W. (2014). Research design: qualitative, quantitative and mixed method approaches. Thosand Oaks, California: Sage Publication.

Curiculum Development Division. (2014). Dokumen Standard Kurikulum dan Pentaksiran Matematik Tahun 5. Putrajaya: Malaysia Ministry of Education.

Curriculum Development Centre. (2012). Malaysia education blueprint 2013-2025. Kuala Lumpur: Malaysia Ministry of Education.

Cynthia, N. H., Margaret, M. F. \& Margaret, E. S. (2018). Effects of direct instruction on reading comprehension for individuals with autism or developmental disabilities. Education and Training in Autism and Developmental Disabilities, 53(2), 176-191.

Deutsch, E. (2019). Direct instruction mathematics in an alternate setting: A teacher resource (Unpublished master thesis). Vancouver Island University, Nanaimo, Canada.

Ellis, A. K., \& Bond, J. B. (2018). Research on educational innovations. New York: Routledge.

Fraenkel, J. R., Wallen, N. E., \& Hyun, H. H. (2015). How to design and evaluate research in education. New York: McGraw Hill Education.

Gardner, M. K. (2015). Mixed-methods research. In R. F. Jack, E. W. Norman, \& H. H. Helen (Eds.), How to design and evaluate research in education (pp. 555-556). New York: McGraw Hill Education.

Ghavifekr, S., \& Rosdy, W. A. W. (2016). Teaching and learning with technology: Effectiveness of ICT integration in schools. International Journal of Research in Education and Science, 1, 175-191. 
Godfrey, D., \& Brown, C. (2018). How effective is the research and development ecosystem for England's schools? London Review of Education, 16(1), 136-151.

Graham, M. A., Mokgwathi, M. S., \& Fraser, W. (2018). The relationship between grade 9 teacher's and learner's perceptions and attitudes with their mathematics achievement. International Journal of Instruction, 12(1), 841-850.

Haris, M., Yunus, M., \& Badusah., J. (2017). The effectiveness of using padlet in ESL classroom. International Journal of Advanced Research, 5(2), 783-788.

Hasler, H. M., \& Akshoomoff, N. (2019). Mathematics ability and related skills in preschoolers born very preterm. Child Neuropsychology, 25(2), 162-178.

Hem, D., \& Ravinesh, C. (2017). Using the revised bloom taxonomy to clasify learning objectives in mathematics: An exploratory study among Fijian secondary pre-service teachers. Journal of Educational Studies, 32(1) 36-50.

Hiebert, J., Miller, E., \& Berk, D. (2017). Relationships between mathematics teacher preparation and graduates' analyses of classroom teaching. The Elementary School Journal, 117(4), 687-707.

Hoyles, C. (2018). Transforming the mathematical practices of learners and teachers through digital technology. Research in Mathematics Education, 20(3), 209-228.

Hussin, A. A. (2018). Education 4.0 made simple: Ideas for teaching. International Journal of Education and Literacy Studies, 6(3), 92-98.

Hyerle, D. (2009). Visual tools for transforming information into knowledge. United States: Corwin Press.

Joyce, B \& Weil, M. (2003). Models of teaching. New Delhi: Prentice-Hall of India.

Kleinsmith, C. L. (2017). The effects of using Padlet on the academic performance and engagement of students in a fifth grade basic skills mathematics classroom (Unpublished master thesis). Rowan University, New Jersey, United States.

Kloosterman, P. (2010). Mathematics skills of 17-year-olds in the United States: 1978 to 2004. Journal for Research in Mathematics Education, 41(1), 20-51.

Kor, L., Teoh, S., Mohamed, S.S.E., \& Singh, P. (2019). Learning to make sense of fractions: Some insights from the Malaysian primary 4 pupils. International Electronic Journal for Mathematics Education, 14(1), 169-182.

Lai, H. J. (2017). Examining civil servants' decisions to use web 2.0 tools for learning, based on the decomposed theory of planned behavior. Interactive Learning Environments, 25(3), 295-305.

Lamon, S. J. (2008). Teaching fractions and ratios for understanding: Essential content knowledge and instructional strategies for teachers. New Jersey: Lawrence Erlbaum Associates.

Lee, J. E. (2017). Preschool teachers' pedagogical content knowledge in mathematics. 
International Journal of Early Childhood 49(2), 229-243.

Ng, W. L., Teo, B. C., Yeo, J. B. W., Ho, W. K., \& Teo, K. M. (2019). Use of technology in mathematics education. In T. L. Toh, B. Kaur, \& E. G. Tay (Eds.), Mathematics education in Singapore (pp. 312-344). Singapore: Springer.

Orey, D. C., \& Rosa, M. (2018). Developing a mathematical modelling course in a virtual learning environment. ZDM - Mathematics Education, 50(2), 173-185.

Putri, M. E. M., \& Saputro, D. R. S. (2019). The effect of application of REACT learning strategies on mathematics learning achievements: Empirical analysis on learning styles of junior high school students. Int $J$ of Edu Res Review 4(2), 231-237.

Shapira, L. O., \& Zavelevsky, E. (2019). Multiple appereances of parental interactions and maths achievement on TIMSS international assessment. International Journal of Sciences and Mathematic Education, 17(2), 1-17.

Simamora, R. E., Saragih, S., \& Hasratuddin, H. (2018). Improving students' mathematical problem solving ability and self-efficacy through guided discovery learning in local culture context. Int E Journal of Mathematics Education, 14(1), 61-71.

UNESCO Institute for Statistics. (2017). Literacy rates continue to rise from one generation to the next. UNESCO. Retrived from http://uis.unesco.org/en/news/international-literacy-day2017.

Wijaya, A. (2017). The relationships between Indonesian fourth graders' difficulties in fractions and the opportunity to learn fractions: A snapshot of TIMSS results. International Journal of Instruction, 10(4), 221-236.

Ye, A., Resnick, I., Hansen, N., Rodrigues, J., Rinne, L., \& Jordan, N. C. (2016). Pathways to fraction learning: Numerical abilities mediate the relation between early cognitive competencies and later fraction knowledge. Journal of Experimental Child Psychology, 152, 242-263.

Yusmarni, Y. (2018). Peningkatan aktivitas dan kemampuan matematis siswa melalui pendekatan konstruktivisme. IJER (Indonesian J of Educational Research), 1(1), 17-26.

Zaranis, N., \& Synodi, E. (2017). A comparative study on the effectiveness of the computer assisted method and the interactionist approach to teaching geometry shapes to young children. Education and Information Technologies, 22(4), 1377-1393.

Zhao, D., Ho, W. K., Toh, P. C., Hang, K. H., \& Teo, K. M. (2019). Beyond school mathematics. In T. L. Toh; B. Kaur; \& E. G. Tay (Eds.). Mathematics education in Singapore (pp. 67-100). Singapore: Springer. 